\section{Getting to a New Normal: Mandating That Patients Wear Masks as Hospitals Fully Reopen during the Coronavirus Pandemic}

\section{To the Editor:}

W ith community spread of coronavirus disease 2019 W (COVID-19) infection, a hospital-acquired infection by both patients and medical providers is a major concern. In an early report from China, among 138 confirmed cases with COVID-19 infection, 57 patients (41.3\%) were considered a nosocomial infection from the hospital. ${ }^{1}$ More than $70 \%$ of suspected nosocomial infection patients were healthcare providers. The authors reported that one of the surgical patients infected 10 healthcare providers. According to an official report on March 6, 2020, more than 3,000 medical professionals have contracted COVID-19 in Hubei province alone, and some have died. ${ }^{2}$ At least 2,629 medical providers in Italy have been infected by this devastating virus. ${ }^{3}$ In the United States, it was reported on April 14, 2020, that 9,000 health workers contracted COVID-19, and 27 of them have died. ${ }^{4}$ Protection of healthcare providers, particularly those on the front line in the emergency departments, wards, and intensive care units, is an extremely important task during the pandemic due to their limited numbers and the need for them to take care of the surging number of patients. It is also critical to protect other uninfected hospital patients and nonmedical staff.

Hospitals have the highest density of patients with COVID-19; thus, hospital-acquired infection should be a top priority task in our daily clinical practice. Medical providers have priority for protective resources, such as masks, for better protection. All healthcare providers should wear regular surgical masks for all patient encounters, based on the successful experience from Singapore and Hong Kong during the pandemic. ${ }^{5}$ However, to mandate that all patients wear masks may have much greater effectiveness in controlling nosocomial infection. Scientific findings related to the aerosol spreading and deposition pattern from breathing, coughing, sneezing, and speaking clearly indicated that placing a tight surgical mask on the patient resulted in a 288-fold greater protection than the wearing of an N95 respirator mask by a receiver (medical provider or anyone in the hospital), as indicated in table 1.,7 COVID-19 is a highly infectious disease that can be transmitted via an aerosol route even when a patient is asymptomatic. Until we can perform high-efficacy screening tests in a short period of time, it is difficult to know who has the disease. A recent clinical study clearly demonstrated that surgical masks reduce coronavirus outward transmission. ${ }^{8}$ To prevent hospital-acquired infection, we initiated and recommend a new hospital policy to mandate that everyone entering the hospital must wear a mask, and the mask cannot be removed unless necessary for a medical intervention or drinking and eating. This policy should apply to everyone in the hospital, including all medical providers, healthcare workers, secretaries, supporting individuals, patients, and patient family members. Ensuring that patients wear a mask could potentially be more critical than masks on the care team. We can protect our staff in a better manner by managing infectious source control. In addition to the new policy, proper education and compliance reinforcement are needed. We have a dedicated entrance in our hospital with trained personnel to check the temperature, ensure mask wearing, and offer a surgical mask for any person who needs one when entering the hospital.

We have implemented this policy early on, and started a pilot virus test within $48 \mathrm{~h}$ before each surgical procedure, aiming toward a full reopen for "normal" full capacity surgical operations. A formal study has been initiated along with these novel policies. Patients will need to continue to wear masks even if their virus test is negative. We believe that this will lead to optimal outcomes for patients and providers.

\section{Research Support}

Support was provided solely from institutional and/or departmental sources.

\section{Competing Interests}

The authors declare no competing interests.

Renyu Liu, M.D., Ph.D., Lee A. Fleisher, M.D. Perelman School of Medicine at the University of Pennsylvania, Philadelphia, Pennsylvania (L.A.F.). Lee.Fleisher@pennmedicine.upenn.edu

DOI: 10.1097/ALN.0000000000003386

\section{References}

1. Wang D, Hu B, Hu C, Zhu F, Liu X, Zhang J, Wang B, Xiang H, Cheng Z, Xiong Y, Zhao Y, Li Y, Wang $\mathrm{X}$, Peng Z: Clinical characteristics of 138 hospitalized patients with 2019 novel coronavirus-infected pneumonia in Wuhan, China. JAMA 2020. DOI: 10.1001/jama.2020.1585 
Table 1. Relative Protection Factors among Different Patterns of Combinations of Mask Scenarios

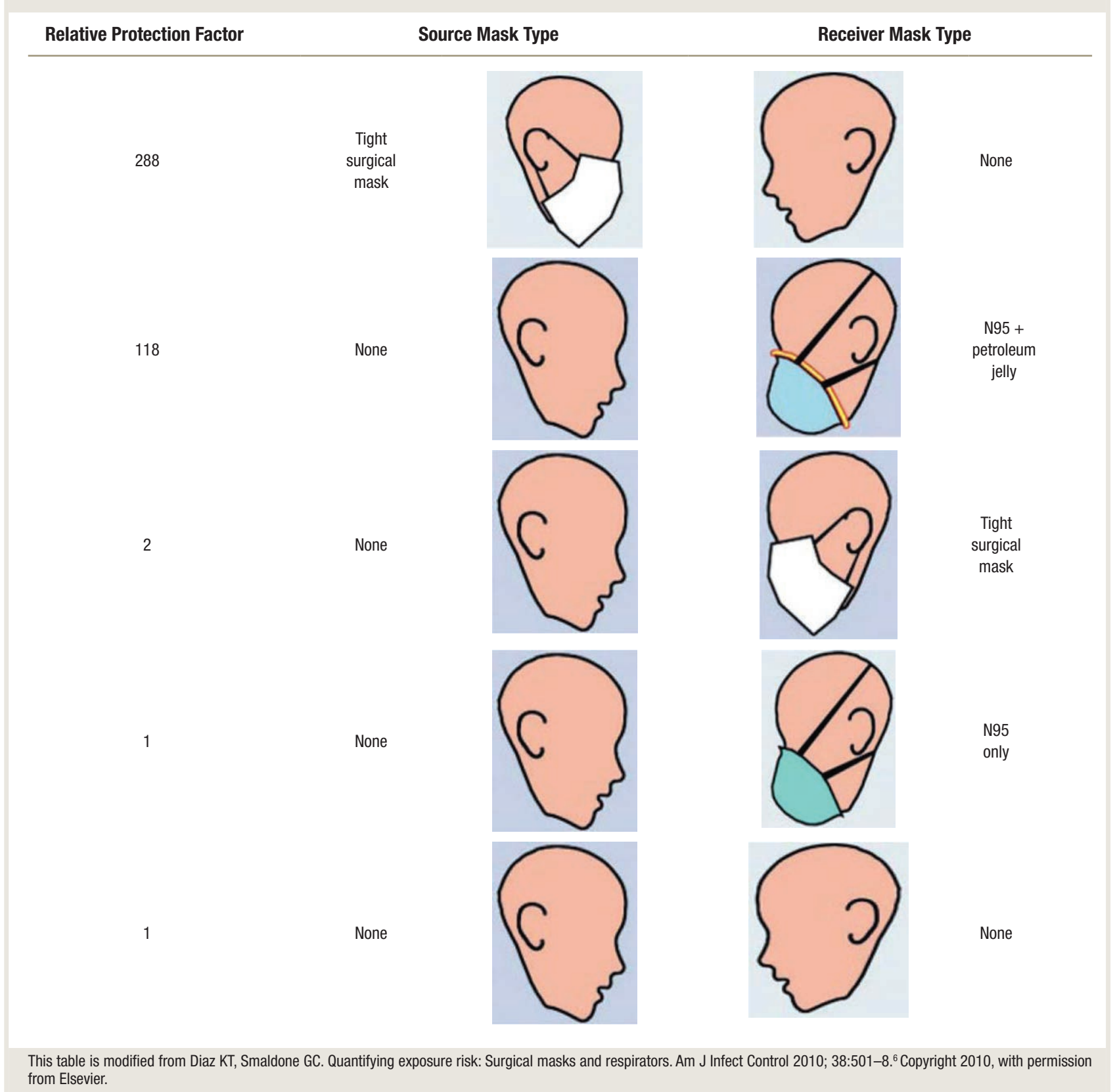

2. More than 3000 medical providers are infected with COVID-19. Daily Economic News 2020. Available at: https://finance.sina.cn/2020-03-06/detail-iimxyqvz8447262.d.html. Accessed April 17, 2020.

3. Oddone E: Thousands of medical staff infected with coronavirus in Italy. 2020, Available at: https://www. aljazeera.com/news/2020/03/rising-number-medical-staff-infected-coronavirus-italy-200318183939314. html. Accessed April 5, 2020.

4. Characteristics of health care personnel with COVID19 - United States, February 12-April 9, 2020.
MMWR Morb Mortal Wkly Rep 2020. DOI: http:// dx.doi.org/10.15585/mmwr.mm6915e6

5. Gawande A. Keeping the coronavirus from infecting health-care workers: What Singapore's and Hong Kong's success is teaching us about the pandemic. 2020. Available at: https://www.newyorker.com/news/ news-desk/keeping-the-coronavirus-from-infecting-health-care-workers. Accessed April 8, 2020.

6. Diaz KT, Smaldone GC: Quantifying exposure risk: Surgical masks and respirators. Am J Infect Control 2010; 38:501-8 
7. O'Riordan TG, Smaldone GC: 11 - Aerosol deposition and clearance, Murray and Nadel's Textbook of Respiratory Medicine, 6th edition). Edited by Broaddus VC, Mason RJ, Ernst JD, King TE, Lazarus SC, Murray JF, Nadel JA, Slutsky AS, Gotway MB. Philadelphia, W.B. Saunders, 2016, pp 168-183.e2

8. Leung NHL, Chu DKW, Shiu EYC, Chan K-H, McDevitt JJ, Hau BJP, Yen H-L, Li Y, Ip DKM, Peiris
JSM, Seto W-H, Leung GM, Milton DK, Cowling BJ: Respiratory virus shedding in exhaled breath and efficacy of face masks. Nat Med 2020. DOI: https://doi.org/10.1038/s41591-020-0843-2

(Accepted for publication April 29, 2020.) 